\title{
Fluoroquinolone Resistance Pattern among the Bacterial Pathogens Causing Urinary Tract Infection in a Tertiary Care Hospital, Kottayam, Kerala
}

\author{
Geethu Anand Thoovakkunnon ${ }^{1}$, Beena V.G. ${ }^{2}$ \\ 1,2 Department of Microbiology, Government Medical College, Kottayam, Kerala, India.
}

\section{ABSTRACT}

\section{BACKGROUND}

Urinary tract infection (UTI) is a very important reason for increased hospital stay, increased morbidity and mortality in the hospital setting. Annually, about 150 million people are diagnosed with UTI worldwide. ${ }^{1}$ The fluoroquinolones have assumed an important role in the therapy of UTI. But the prevalence of urinary tract infections caused by fluoroquinolone-resistant bacteria has been increasing over the years. The purpose of this study was to evaluate fluoroquinolone resistance pattern among the bacterial pathogens causing urinary tract infections.

\section{METHODS}

This is a cross-sectional descriptive study. A total of 200 urine samples were collected from clinically suspected UTI patients, attending out-patient department (OPDs) and were admitted to various wards of our hospital. The samples were inoculated using the standard loop, incubated aerobically, isolates were identified by standard biochemical reactions and antibiotic susceptibility testing was performed.

\section{RESULTS}

Out of 200 samples, the most common organism isolated was Escherichia coli (57 $\%)$, followed by Klebsiella pneumoniae subsp pneumonia (27 \%). $93.9 \%$ of Escherichia coli and $100 \%$ of Klebsiella pneumoniae subsp pneumoniae isolates were resistant to ampicillin. The present study also documented high level of fluoroquinolone resistance among almost all common uropathogens. Among Escherichia coli and Klebsiella pneumoniae subsp pneumoniae; ciprofloxacin resistance was $77.2 \%$ and $85.2 \%$ respectively. Quinolone resistance was found to be more common in hospitalised patients and catheterized patients. According to our study, although levofloxacin is far effective than ciprofloxacin for uropathogens, the resistance to both are increasing.

\section{CONCLUSIONS}

The results presented in this study indicate that it is time to reconsider the frequent use of fluoroquinolones. Use of fluoroquinolones to treat patients before getting the sensitivity pattern of the isolate should be stopped. It is mandatory to formulate antimicrobial policy according to the local resistance pattern. Resistance pattern must be assessed in hospital and laboratory-based surveillance studies.

\section{KEY WORDS}

Urinary Tract Infections, Escherichia coli, Antibiotic Sensitivity, Fluoroquinolones
Corresponding Author:

Dr. Beena V.G.,

Associate Professor,

Department of Microbiology,

Government Medical College,

Kottayam, Kerala, India.

E-mail: drbeenavg93@gmail.com

DOI: $10.14260 /$ jemds $/ 2021 / 777$

How to Cite This Article:

Thoovakkunnon GA, Beena VG. Fluoroquinolone resistance pattern among the bacterial pathogens causing urinary tract infection in a tertiary care hospital, Kottayam, Kerala.J Evolution Med Dent Sci 2021;10(45):3843-3848, DOI: $10.14260 /$ jemds/2021/777

Submission 05-11-2021,

Peer Review 13-11-2021,

Acceptance 03-12-2021,

Published 21-12-2021.

Copyright (C) 2021 Geethu Anand Thoovakkunnon et al. This is an open access article distributed under Creative Commons Attribution License [Attribution 4.0 International (CC BY 4.0)] 


\section{BACKGROUND}

Urinary tract infection is defined as a spectrum of disease caused by microbial invasion of the genitourinary tract that extends from the renal cortex of the kidney to the urethral meatus. ${ }^{2}$ It is one of the commonest bacterial infections affecting people of both; in the community and in hospitals. ${ }^{3}$ Even though UTI is more commonly seen in females, it can affect both genders of any age.

The manifestations of UTI may vary from mild asymptomatic cystitis to pyelonephritis and septicaemia. ${ }^{4}$ Complications of untreated UTI include kidney damage, renal scarring, and renal failure.

UTI is commonly caused by bacteria mostly by Gramnegative bacteria such as Escherichia coli, Klebsiella species, enterobacter, acinetobacter species, Pseudomonas aeruginosa, proteus species, and citrobacter species. Staphylococcus saprophyticus, enterococcus species, and Coagulase-negative staphylococcus are also responsible for causing UTI. 5

The most common causative agent for both uncomplicated and complicated UTI is uropathogenic Escherichia coli (UPEC). ${ }^{6}$

In most of the cases, broad-spectrum antimicrobials such as ampicillin, cephalosporins, fluoroquinolones, and aminoglycosides are usually started before the urine culture results are available. The indiscriminate use of such antimicrobial agents was the main reason behind the emergence and spread of antimicrobial resistance among microorganisms. ${ }^{7}$

Ciprofloxacin and norfloxacin are the most commonly prescribed fluoroquinolones for UTI because of their excellent activity against pathogens commonly encountered in UTI and broad Gram-negative organism coverage. Fluoroquinolones are one of few available therapies for serious salmonella spp and Escherichia coli infections. Therefore, resistance to fluoroquinolones can have serious clinical consequences. Resistance to fluoroquinolones emerges quickly, so they should be used with caution and reserved for severe infections. ${ }^{1}$

Mechanism of resistance includes spontaneously occurring mutations in DNA gyrase or DNA topoisomerase IV. Mutations occur in genes that control the expression of efflux pumps and defective function of porin channels. ${ }^{8}$

There is a rising trend of antimicrobial resistance in urinary pathogens. Knowledge of the antimicrobial resistance patterns of common uropathogens is essential to provide clinically appropriate and cost-effective therapy. The knowledge of antimicrobial resistance patterns is also important in order to achieve a favourable clinical outcome and a reduction in antimicrobial resistance.

\section{Aims and objectives}

1. To find out the prevalence of various pathogens causing urinary tract infection.

2. To find out the antibiotic susceptibility pattern of pathogens causing urinary tract infection.

3. To find out the fluoroquinolone resistance pattern among the urinary pathogens.

4. To find out the factors influencing the fluoroquinolone resistance among the urinary pathogens.

\section{Inclusion Criteria}

All urine samples from patients with clinically suspected urinary tract infection with urine culture showing significant bacteriuria, received in the microbiology laboratory, Government Medical College, Kottayam.

\section{Exclusion Criteria}

1. Patient on antibiotic treatment.

2. Organisms other than bacterial pathogens like fungus.

\section{METHODS}

This cross-sectional descriptive study was carried out in the Department of Microbiology, Government Medical College, Kottayam, India, from December 2018 to December 2019.

Urine samples were collected from clinically suspected UTI patients, attending OPDs and who were admitted to various wards of our hospital. Early morning midstream clean catch urine was collected in a universal container; suprapubic aspirated urine and, catheter urine sample are included. The patients were given instructions on how to collect samples to avoid urethral contamination. The samples are immediately transferred and processed within 2 hours of collection in the laboratory. In case of delay, the samples are stored at $4^{\circ} \mathrm{C}$. Samples received in the microbiology laboratory are subjected to wet film examination, Gram stain and culture.

For culture, a standard loopful of urine was inoculated on $5 \%$ blood agar, MacConkey's agar and cysteine lactose electrolyte deficient agar (CLED) by semi quantitative culture method. For semi quantitative culture, the calibrated loop was inserted vertically into the well mixed urine and spread the loopful over the sector of a plate and streak out from that sector over other sectors produce isolated colonies. ${ }^{9}$ The plates are incubated overnight at $37^{\circ} \mathrm{c}$ and examined for growth after 24 hours.

Culture positive for bacterial pathogens with significant bacteriuria was included in the study. Significant bacteriuria was determined as $\geq 10^{5} \mathrm{CFU} / \mathrm{ml}$ of midstream urine, $\geq 10^{2}$ $\mathrm{CFU} / \mathrm{ml}$ of a catheter specimen. For suprapubic urine, significant growth is obtained even if bacterial numbers are below $10^{5} / \mathrm{ml}^{9}$.

The isolates were identified based on staining, culture and biochemical properties using standard guidelines. ${ }^{10}$ Antibiotic sensitivity testing of bacterial isolates was done by Kirby-Bauer disc diffusion method with 0.5 McFarland standard turbidity of inoculum on Mueller Hinton agar. The antibiotic discs were selected according to the organism isolated. The susceptibility and resistance pattern are studied and interpreted according to clinical and laboratory standard institute (CLSI) guidelines. ${ }^{11}$ The isolates that are resistant to ciprofloxacin were tested for other fluoroquinolones. The antibiotics selected in the study were ampicillin, gentamicin, amikacin, cefazolin, trimethoprim sulfamethoxazole, nitrofurantoin, piperacillin tazobactam, cefoperazone sulbactam, meropenem, ceftazidime, penicillin, high level gentamicin, vancomycin, nitrofurantoin, linezolid, tetracycline, nalidixic acid, ciprofloxacin, norfloxacin, ofloxacin, levofloxacin. 


\section{Statistical Analysis}

The data was coded and entered in Microsoft Excel and further analysis was done by software Statistical Package for Social Sciences (SPSS) version 16 and the results were expressed as frequency and percentage. Results were compiled in tabular and graphical representation using Microsoft Excel 2007 and Microsoft Word 2007.

\section{RESULTS}

A total of 200 urine samples were included during the study period. Of these, prevalence of UTI was found to be high in females $(62.5 \%)$ than males (37.5\%). Out of the 200 patients, most common age group affected was 61 - 70 years (22.5\%) (Graph 1)

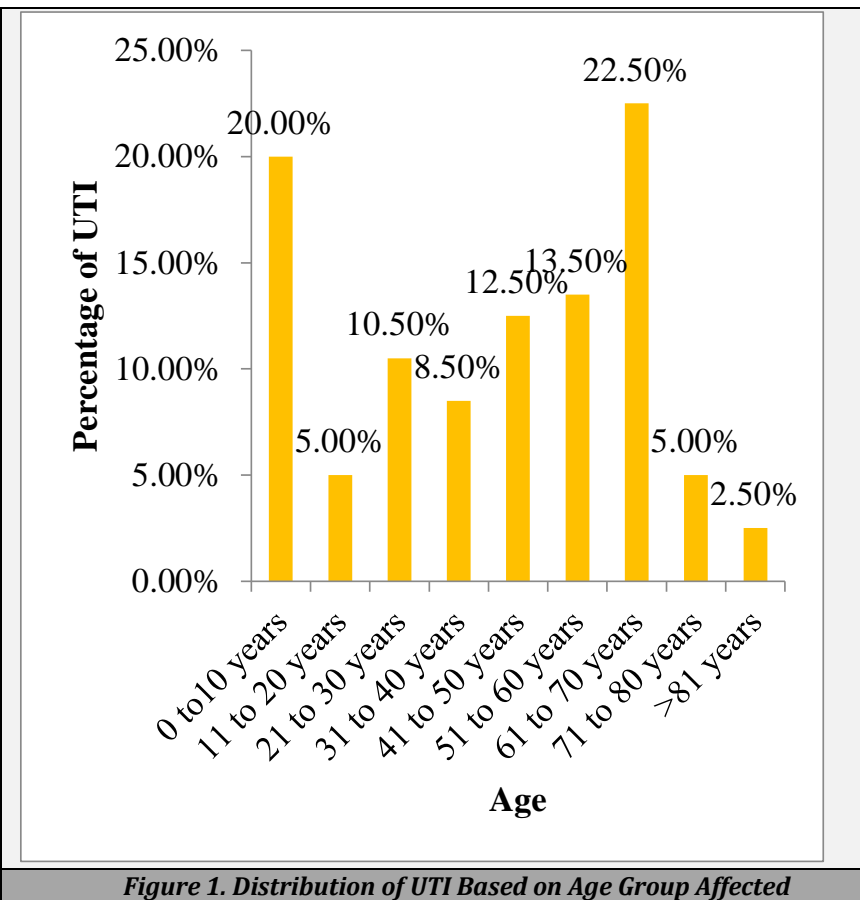

\begin{tabular}{|ccc|}
\hline & Frequency & Percentage \\
Escherichia coli & 114 & $57.0 \%$ \\
Klebsiella pneumoniae subsp pneumoniae & 54 & $27.0 \%$ \\
Pseudomonas aeruginosa & 18 & $9.0 \%$ \\
Enterobacter cloacae & 2 & $1.0 \%$ \\
Enterococcus faecalis & 3 & $1.5 \%$ \\
Acinetobacter baumannii & 3 & $1.5 \%$ \\
Proteus vulgaris & 3 & $1.5 \%$ \\
Proteus mirabilis & 2 & $1.0 \%$ \\
Citrobacter freundii & 1 & $0.5 \%$ \\
Total & $\mathbf{2 0 0}$ & $\mathbf{1 0 0 . 0} \%$ \\
\hline Table 1. Organisms Isolated & \\
\hline
\end{tabular}

Out of 200 samples, more number of samples were obtained from inpatients $(62.5 \%)$ than outpatients $(37.5 \%)$. Out of 125 inpatient samples, 21 (16.8\%) were catheter samples. Out of 200 samples, majority of isolates were Gram negative organisms (98.5\%). Gram positive organisms constitute only $1.5 \%$. The findings of this study indicate that Escherichia coli (57\%) was the predominant uropathogen, followed by Klebsiella pneumoniae subsp pneumoniae (27\%), Pseudomonas aeruginosa (9\%)(Table 1).

Escherichia coli was also the major pathogen isolated both from OPD (74.7 \%) and IPD (46.4\%). Klebsiella pneumoniae subsp pneumonia was the second most common pathogen isolated from both outpatients (20\%) and inpatients (31.2 $\%)$.

Escherichia coli was the predominant uropathogen in catheter associated UTI (42.8\%), followed by Pseudomonas aeruginosa (23.8\%) and Klebsiella pneumoniae subsp pneumoniae (19\%) (Table 2).

\begin{tabular}{|ccc|}
\hline Organism Isolated & Frequency & Percentage \\
\hline Escherichia coli & 9 & $42.8 \%$ \\
Klebsiella pneumoniae subsp pneumoniae & 4 & $19.0 \%$ \\
\hline Pseudomonas aeruginosa & 5 & $23.8 \%$ \\
Proteus vulgaris & 2 & $9.5 \%$ \\
Proteus mirabilis & 1 & $4.73 \%$ \\
\hline Table 2. Distribution of Organisms Causing Catheter \\
\multicolumn{2}{|c|}{ Associated Urinary Tract Infection } \\
\hline
\end{tabular}

Among the 114 Escherichia coli isolates, only 7 isolates (6.1\%) were sensitive to ampicillin. Among the 54 Klebsiella pneumoniae subsp pneumoniae isolates, no one is sensitive to ampicillin (0\%). Meropenem had the highest percentage of susceptibility for $E$. coli (98.2\%), and nitrofurantoin ranking second (96.4\%). But K. pneumoniae was most susceptible to nitrofurantoin (98.1\%). $96.2 \%$ isolates were sensitive to meropenem.

$75.2 \%$ Escherichia coli isolates were sensitive to cefoperazone sulbactam and $82.4 \%$ to piperacillin tazobactam. (Table 3)

\begin{tabular}{|c|c|c|c|c|c|c|}
\hline 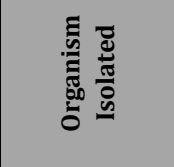 & = & 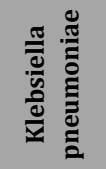 & 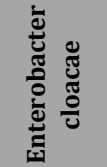 & 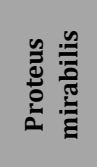 & 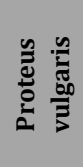 & 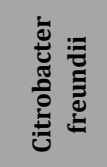 \\
\hline Ampicillin & $\begin{array}{c}7 \\
(6.1 \%)\end{array}$ & $\begin{array}{c}0 \\
(0.00 \%)\end{array}$ & $\begin{array}{c}0 \\
(0.00 \%)\end{array}$ & $\begin{array}{c}0(0.00 \\
\%)\end{array}$ & $\begin{array}{c}0(0.00 \\
\%)\end{array}$ & $\begin{array}{c}0 \\
(0.00 \%)\end{array}$ \\
\hline Gentamicin & 66 (57.8 \%) & $\begin{array}{c}30(55.6 \\
\%)\end{array}$ & $\begin{array}{c}1 \\
50.0 \%)\end{array}$ & $\begin{array}{c}2(100.0 \\
\%)\end{array}$ & $\begin{array}{c}1(33.3 \\
\%)\end{array}$ & $\begin{array}{c}1 \\
(100.0 \%)\end{array}$ \\
\hline Amikacin & $\begin{array}{c}91 \\
(79.8 \%)\end{array}$ & $\begin{array}{c}38(70.3 \\
\%)\end{array}$ & $\begin{array}{c}2(100.0 \\
\%)\end{array}$ & $\begin{array}{c}2(100.0 \\
\%)\end{array}$ & $\begin{array}{c}1(33.3 \\
\%)\end{array}$ & $\begin{array}{c}1 \\
(100.0 \%)\end{array}$ \\
\hline $\begin{array}{l}\text { Ceph } \\
1 \text { st g }\end{array}$ & $\begin{array}{c}20 \\
(17.5 \%)\end{array}$ & $\begin{array}{c}7 \\
(12.9 \%)\end{array}$ & $\begin{array}{c}1 \\
(50.0 \%)\end{array}$ & $0.00 \%$ & $\begin{array}{c}0(0.00 \\
\%)\end{array}$ & $\begin{array}{c}1 \\
(100.0 \%)\end{array}$ \\
\hline Cefotaxime & $\begin{array}{c}32 \\
(28.1 \%)\end{array}$ & $\begin{array}{c}15(27.8 \\
\%)\end{array}$ & $\begin{array}{c}1 \\
(50.0 \%)\end{array}$ & $\begin{array}{c}2(100.0 \\
\%)\end{array}$ & $\begin{array}{c}1(33.3 \\
\%)\end{array}$ & $\begin{array}{c}1 \\
(100.0 \%)\end{array}$ \\
\hline $\begin{array}{r}\text { Cefoper } \\
\text { sulbac }\end{array}$ & $\begin{array}{r}88 \\
(75.29\end{array}$ & $\begin{array}{c}30(55.5 \\
\%)\end{array}$ & $\begin{array}{r}0 \\
0.00\end{array}$ & $\begin{array}{c}2(100.0 \\
\%)\end{array}$ & $\begin{array}{c}1(33.3 \\
\%)\end{array}$ & $\begin{array}{c}1 \\
(100.0 \%)\end{array}$ \\
\hline $\begin{array}{l}\text { Piperacillin } \\
\text { tazobactam }\end{array}$ & $\begin{array}{c}94 \\
(82.4 \%)\end{array}$ & $\begin{array}{c}33(61.1 \\
\%)\end{array}$ & $\begin{array}{c}2(100.0 \\
\%)\end{array}$ & $\begin{array}{c}2(100.0 \\
\%)\end{array}$ & $\begin{array}{c}2(66.7 \\
\%)\end{array}$ & $\begin{array}{c}1 \\
(100.0 \%)\end{array}$ \\
\hline Meropenem & $\begin{array}{c}112 \\
(98.2 \%)\end{array}$ & $\begin{array}{c}52 \\
(96.2 \%)\end{array}$ & $\begin{array}{c}2(100.0 \\
\%)\end{array}$ & $\begin{array}{c}2(100.0 \\
\%)\end{array}$ & $\begin{array}{c}2(66.7 \\
\%)\end{array}$ & $\begin{array}{c}1 \\
(100.0 \%)\end{array}$ \\
\hline Nitrofurantoin & $\begin{array}{c}110(96.4 \\
\%)\end{array}$ & $\begin{array}{c}34(63.0 \\
\%)\end{array}$ & $\begin{array}{c}2(100.0 \\
\%)\end{array}$ & $\begin{array}{c}0(0.00 \\
\%)\end{array}$ & $\begin{array}{c}0(0.00 \\
\%)\end{array}$ & $\begin{array}{c}1 \\
(100.0 \%)\end{array}$ \\
\hline $\begin{array}{c}\text { Trimethoprim } \\
\text { sulfamethoxazole }\end{array}$ & $\begin{array}{c}54 \\
(47.3 \%)\end{array}$ & $\begin{array}{c}19(35.1 \\
\%)\end{array}$ & $\begin{array}{c}1 \\
(50.0 \%)\end{array}$ & $\begin{array}{c}1(50.0 \\
\%)\end{array}$ & $\begin{array}{c}2(66.7 \\
\%)\end{array}$ & $\begin{array}{c}1 \\
(100.0 \%)\end{array}$ \\
\hline
\end{tabular}

Only $28.1 \%$ of Escherichia coli and $27.8 \%$ Klebsiella pneumoniae subsp pneumoniae were sensitive to cefotaxime. Pseudomonas aeruginosa was most susceptible to meropenem (94.4\%), ceftazidime (88.8\%) and piperacillin tazobactam $(83.3 \%)$.

All isolates of Acinetobacter baumannii were resistant to all antibiotics tested.

Only one Gram positive organism was isolatedEnterococcus faecalis. Enterococcus faecalis was $100 \%$ sensitive to vancomycin, linezolid, and high-level gentamycin but was $100 \%$ resistant to penicillin and $33.3 \%$ sensitive to ampicillin. Among 3 isolates, 2 were sensitive to nitrofurantoin. 
High resistance of quinolones was found in our study as overall resistance for nalidixic acid, ciprofloxacin, and levofloxacin is $85 \%, 78 \%$, and $73 \%$ respectively. Ciprofloxacin resistance was found to be more common in the age group of 61 to 70 years ( $25 \%$ ) followed by 51 - 60 years and $0-10$ years. Ciprofloxacin resistance was found to be more common in females (59.6\%) than males (40.4\%).

Resistance of all quinolones was found to be more in samples collected from inpatients than from outpatients. In our study, no difference in resistance was found between second generation quinolones (Ciprofloxacin, norfloxacin and ofloxacin).

$77.2 \%$ of Escherichia coli isolates were resistant to ciprofloxacin. $71.1 \%$ of Escherichia coli isolates were resistant to levofloxacin. $85.2 \%$ of Klebsiella pneumoniae subsp pneumonia were resistant to ciprofloxacin. $83.3 \%$ of Klebsiella pneumoniae subsp pneumoniae were resistant to levofloxacin. $72.2 \%$ of Pseudomonas aeruginosa were resistant to ciprofloxacin. $66.7 \%$ of Pseudomonas aeruginosa were resistant to levofloxacin (Table 4)

\begin{tabular}{|c|c|c|c|c|c|}
\hline 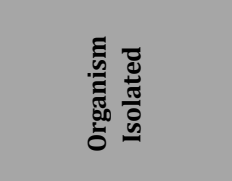 & 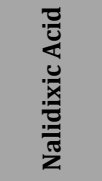 & 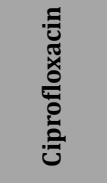 & 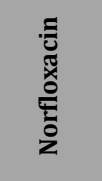 & 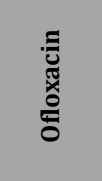 & 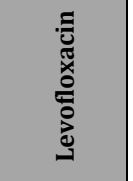 \\
\hline Escherichia coli & $\begin{array}{c}95 \\
(83.3 \%)\end{array}$ & $\begin{array}{c}88 \\
(77.2 \%)\end{array}$ & $\begin{array}{c}88 \\
(77.2 \%)\end{array}$ & $\begin{array}{c}88(77.2 \\
\%)\end{array}$ & $81(71.1 \%)$ \\
\hline $\begin{array}{l}\text { Klebsiella pneumoniae } \\
\text { subspecies pneumonia }\end{array}$ & $\begin{array}{c}47 \\
(87.0 \%)\end{array}$ & $\begin{array}{c}46 \\
(85.2 \%)\end{array}$ & $\begin{array}{c}46 \\
(85.2 \%)\end{array}$ & $\begin{array}{c}46(85.2 \\
\%)\end{array}$ & $\begin{array}{c}45 \\
(83.3 \%)\end{array}$ \\
\hline $\begin{array}{c}\text { Pseudomonas } \\
\text { aeruginosa }\end{array}$ & $\begin{array}{c}18 \\
(100 \%)\end{array}$ & $\begin{array}{c}13 \\
(72.2 \%)\end{array}$ & $\begin{array}{c}13 \\
(72.2 \%)\end{array}$ & $\begin{array}{c}13(72.2 \\
\%)\end{array}$ & $12(66.7 \%)$ \\
\hline Enterobacter cloacae & $\begin{array}{c}2 \\
(100 \%)\end{array}$ & $\begin{array}{c}2 \\
(100 \%)\end{array}$ & $\begin{array}{c}2 \\
(100 \%)\end{array}$ & $\begin{array}{c}2 \\
(100 \%)\end{array}$ & $\begin{array}{c}1 \\
(50.0 \%)\end{array}$ \\
\hline Enterococcus faecalis & $\begin{array}{c}3 \\
(100 \%)\end{array}$ & $\begin{array}{c}2 \\
(66.6 \%)\end{array}$ & $\begin{array}{c}2 \\
(66.6 \%)\end{array}$ & $\begin{array}{c}2 \\
(66.6 \%)\end{array}$ & $\begin{array}{c}2 \\
(66.6 \%)\end{array}$ \\
\hline $\begin{array}{l}\text { Acinetobacter } \\
\text { baumannii }\end{array}$ & $\begin{array}{c}3 \\
(100 \%)\end{array}$ & $\begin{array}{c}3 \\
(100 \%)\end{array}$ & $\begin{array}{c}3 \\
(100 \%)\end{array}$ & $\begin{array}{c}3 \\
(100 \%)\end{array}$ & $\begin{array}{c}3 \\
(100 \%)\end{array}$ \\
\hline Proteus vulgaris & $\begin{array}{c}2 \\
(66.6 \%)\end{array}$ & $\begin{array}{c}1 \\
(33.3 \%)\end{array}$ & $\begin{array}{c}1 \\
(33.3 \%)\end{array}$ & $\begin{array}{c}1 \\
(33.3 \%)\end{array}$ & $\begin{array}{c}1 \\
(33.3 \%)\end{array}$ \\
\hline Proteus mirabilis & $\begin{array}{c}1 \\
(50 \%)\end{array}$ & $\begin{array}{c}0 \\
(0.0 \%)\end{array}$ & $\begin{array}{c}0 \\
(0.0 \%)\end{array}$ & $\begin{array}{c}0 \\
(0.0 \%)\end{array}$ & $\begin{array}{c}0 \\
(0.0 \%)\end{array}$ \\
\hline Citrobacter freundii & $\begin{array}{c}1 \\
(100 \%)\end{array}$ & $\begin{array}{c}1 \\
(100 \%) \\
\end{array}$ & $\begin{array}{c}1 \\
(100 \%) \\
\end{array}$ & $\begin{array}{c}1 \\
(100 \%)\end{array}$ & $\begin{array}{c}1 \\
(100 \%)\end{array}$ \\
\hline
\end{tabular}

All pathogens causing catheter associated urinary tract infection (CAUTI) were found to be $100 \%$ resistant to nalidixic acid and fluoroquinolones except proteus spp. All proteus spp isolated from CAUTI were sensitive to fluoroquinolones.

\section{DISCUSSION}

Escherichia coli was the most common pathogen isolated in our study $(57 \%, 114 / 200)$. This is similar to studies from other parts of India and also from different countries across the world. ${ }^{12,13,14}$

Escherichia coli was also the major pathogen isolated both from outpatients $(74.7 \%)$ and in patients (46.4\%). This was similar to a study by Smita U Shevade et al. in 2013. ${ }^{12}$

The second common pathogen was Klebsiella pneumoniae subsp pneumoniae, accounted for $27 \%$ (54/200) of cases. The findings of a study by Gupta A et al. in Ahmedabad in 2016 also indicate that Escherichia coli (55.1\%) is the predominant pathogen of UTI, followed by Klebsiella spp
(22.3 \%). ${ }^{7}$ In another study, Pseudomonas spp was found as the second most frequent Gram-negative isolate. ${ }^{15}$

Out of 125 inpatient samples obtained in our study, 21 (16.8\%) were catheter samples. A study conducted by Chithra Jayaprakash et al. in Kerala, majority of the pathogens causing hospital acquired UTI were isolated from catheterized patients (84.3\%). ${ }^{16}$ Escherichia coli was the predominant uropathogen in catheter associated UTI (42.8 \%), followed by Pseudomonas aeruginosa (23.8\%) and Klebsiella pneumoniae subsp pneumoniae (19\%).This pattern is similar to a study by Mohammad Mukhit Kazi et al. in Pune. ${ }^{17}$

Escherichia coli was most sensitive to meropenem (98.2 $\%)$. This high susceptibility of Escherichia coli to meropenem was similar to that seen in other studies across India. ${ }^{17,18} \mathrm{In}$ trend with other studies across India, Susceptibility of Escherichia coli to nitrofurantoin was found high at $96.4 \% .^{18}$ A previous study conducted in 2008 by Vasuki Balasubramanyam et al. in Tamilnadu, resistance of Escherichia coli against nitrofurantoin was $20 \%{ }^{19}$

In our study, two most common uropathogens; Escherichia coli and Klebsiella pneumoniae subsp pneumoniae isolates were found to be most resistant to ampicillin. Such high level of resistance to ampicillin was documented from various studies from different parts of India. ${ }^{17} 52.7 \%$ isolates of Escherichia coli were resistant to cotrimoxazole in this study. It is almost similar to a study by Manjunath et al. from Karnataka (47.9\%). ${ }^{20}$

Third-generation cephalosporins had up to $71.9 \%$ resistance in our study. This is important because all inpatients with UTI are empirically started on third-generation cephalosporins.

In our study, $75.2 \%$ of Escherichia coli were sensitive to cefoperazone, sulbactam and $82.4 \%$ to piperacillin tazobactam. These findings are almost similar to a study by Sundaramoorthy et al. ${ }^{21}$ in South India. High sensitivity of Pseudomonas aeruginosa to meropenem and ceftazidime was found similar to other studies. ${ }^{5}$

Acinetobacter baumannii was highly resistant in our study. All 3 isolates were resistant to all antibiotics tested. Multi drug resistant Acinetobacter baumannii is highly complicated to treat and has become a global threat over the past few years. ${ }^{22}$

The fluoroquinolones resistance among uropathogens is increasing over the years due to the extensive use and misuse of fluoroquinolones. The overuse of fluoroquinolones may increase the risks of resistance and the cost of medical care. ${ }^{7}$ According to a study, nitrofurantoin may be considered as an alternative to fluoroquinolones when the resistance to fluoroquinolone in the population exceeds $12 \% .^{23}$

In our study, ciprofloxacin resistance was found to be more common in females (59.6\%) than males (40.4\%). It is similar to a study by Tippireddypalli Gururajuetal et al. ${ }^{4}$ But in that study majority of the ciprofloxacin resistant isolates $(28$ $\%)$ were from the age group of 56 - 60 years. In our study, age group of 61 to 70 years ( $25 \%$ ) were the most common group. According to a study by $\mathrm{P}$. Rattanaumpawana et al. fluoroquinolone resistance was found to be more in male patients. ${ }^{24}$

Similar to our study, study in Tirupati in 2015 also found that, Resistance of all quinolones were found to be more in samples collected from IPD than OPD. According to that 
study, this may be due to decreased immune system along with hospital acquired infections and with indwelling catheters and with complicated infections. ${ }^{25}$ High resistance of fluoroquinolone were found in various studies in India and worldwide $6,12,14,25$ which is clearly indicated in our study too as resistance for ciprofloxacin is $78 \%$ overall, and, for levofloxacin, it is $73 \%$.

No difference in resistance was found between second generation quinolones (Ciprofloxacin, norfloxacin and ofloxacin). But in a study by Nandihal NW et al. in Hubli, resistance to ciprofloxacin and norfloxacin was $79 \%$ and 71 \% respectively among Escherichia coli isolates. ${ }^{26}$

In a study by Jharna Mandal et al. in Puducherry, $73 \%$ of all Escherichia coli isolates were found to be resistant to ciprofloxacin. Ciprofloxacin resistance was comparatively less among the other Gram-negative uropathogens like pseudomonas spp, proteus spp and Klebsiella pneumoniae. ${ }^{27}$ But in our study, ciprofloxacin resistance was high among all Gram-negative uropathogens.

Resistance to levofloxacin was $73 \% .10$ ciprofloxacin resistant isolates were found to be sensitive to levofloxacin. It clearly indicates the efficacy of higher generation fluoroquinolones. A study by Anirudh Gupta et al. in 2015 also reported that levofloxacin (46.2\%) is far more effective then ciprofloxacin $(14.5 \%)$ against the uropathogens, but there is an increasing resistance to both. ${ }^{7}$ Tada Dharmishtha et al. did a study in Gandhinagar in 2012. Among the $\beta$-lactam antibiotics, imipenem had the widest coverage against Escherichia coli isolates (100 \%), followed by fluoroquinolones (levofloxacin $95 \%$ ). ${ }^{28}$

In our study, resistance to nalidixic acid was high in Klebsiella pneumoniae subsp pneumonia than Escherichia coli. It was similar to a study by Nandihal NW et al.26 in 2014 where the resistance was $91 \%$ for Escherichia coli and $94 \%$ for Klebsiella spp. Contradictory to our study, In that study, ciprofloxacin resistance was more in Escherichia coli than Klebsiella spp.

$71.1 \%$ of Escherichia coli isolates (81/114) were resistant to levofloxacin in our study.

In the study done by Karlowsky, ${ }^{29}$ the ciprofloxacin resistance was $15.8 \%$, moreover, $5.1 \%$ resistance for levofloxacin was reported in the same study. In another study, ${ }^{30}$ levofloxacin resistance among uropathogens was 17 $\%$.

For Pseudomonas aeruginosa isolates, in the study done by Karlowsky, the ciprofloxacin and levofloxacin resistance was $26.5 \%$ and $27 \%$, respectively. ${ }^{29}$ However in our study, the resistance for Pseudomonas aeruginosa isolates was 66.7 $\%$ and $72.2 \%$ for levofloxacin and ciprofloxacin, respectively.

In the study done by Akram et al. all acinetobacter spp isolates were fluoroquinolone sensitive. ${ }^{31}$ However, in our study, acinetobacter spp were $100 \%$ resistant to all fluoroquinolones. In another study, the resistance was $66.7 \%$ and $87.7 \%$ for levofloxacin and ciprofloxacin, respectively. ${ }^{7}$

In our study, Proteus mirabilis was $100 \%$ sensitive to ciprofloxacin and levofloxacin. In a study by $P$. Rattanaumpawana, ciprofloxacin resistance was $11.4 \%$ in proteus spp and $20.2 \%$ in enterobacter spp. ${ }^{24} 100 \%$ of isolates of Escherichia coli, Klebsiella pneumoniae subsp pneumoniae and Pseudomonas aeruginosa obtained from catheter samples were resistant to nalidixic acid, ciprofloxacin, norfloxacin, ofloxacin and levofloxacin.
Banerjee $\mathrm{T}$ et al. in his study also found that presence of urinary catheters is a risk factor for fluoroquinolone resistance. ${ }^{25}$

\section{CONCLUSIONS}

Urinary tract infection is one of the most common infections in both outpatients and hospitalized patients. Early diagnosis and prompt treatment of UTI is essential to prevent long term complications such as renal scarring, hypertension, and chronic renal failure.

The most common organism isolated in the present study was Escherichia coli (57 \%), followed by Klebsiella pneumoniae subsp pneumonia (27\%).

Highest sensitivity of meropenem to Escherichia coli was reported in our study. Nitrofurantoin also has sensitivity which was comparable to that of meropenem.

The fluoroquinolones have assumed an important role in the therapy of UTI because of their broad-spectrum activity, lesser side effects and convenient oral dosages. But the prevalence of urinary tract infections caused by fluoroquinolone-resistant bacteria has been increasing over the years.

The present study also documented a high level of fluoroquinolone resistance among almost all common uropathogens. Among Escherichia coli and Klebsiella pneumoniae subsp pneumoniae; ciprofloxacin resistance was $77.2 \%$ and $85.2 \%$ respectively.

Quinolone resistance was found to be more common in hospitalised patients and catheterized patients. Ciprofloxacin resistance was found to be more common in the age group of 61 to 70 years and more common in females.

According to our study, although levofloxacin is far effective than ciprofloxacin for uropathogens, the resistance to both are increasing among uropathogens.

It was observed that resistance to routinely prescribed urinary antibiotics such as norfloxacin has been introduced even in outpatients. It is also very clear to develop strategies to counteract the development of further antimicrobial resistance.

Nitrofurantoin was found to be slightly more efficacious and less prone to resistance by uropathogens in this study. So nitrofurantoin can be considered as a safe alternative to fluoroquinolones in the therapy of acute uncomplicated UTI.

Data sharing statement provided by the authors is available with the full text of this article at jemds.com.

Financial or other competing interests: None.

Disclosure forms provided by the authors are available with the full text of this article at jemds.com.

\section{REFERENCES}

[1] Fasugba 0, Gardner A, Mitchell BG, et al. Ciprofloxacin resistance in community- and hospital-acquired Escherichia coli urinary tract infections: a systematic review and meta-analysis of observational studies. BMC Infect Dis 2015;15:545.

[2] Shakya P, Shrestha D, Maharjan E, et al. ESBL production among E. coli and Klebsiella spp. causing urinary tract 
infection: a hospital based study. Open Microbiol J 2017;11:23-30.

[3] Muzammil M, Adnan M, Sikandar SM, et al. Study of culture and sensitivity patterns of urinary tract infections in patients presenting with urinary symptoms in a tertiary care hospital. Cureus 2020;12(2):e7013.

[4] Gururaju T, Sarojamma V, Ramakrishna V. Prevalence and fluoroquinolone resistance pattern in escherichia coli isolates of urinary tract infection (UTI) patients. 2015;4(2):56-64.

[5] Ahmed SS, Shariq A, Alsalloom AA, et al. Uropathogens and their antimicrobial resistance patterns: relationship with urinary tract. Int $\mathrm{J}$ Health Sci (Qassim) 2019;13(2):48-55.

[6] Flores-Mireles AL, Walker JN, Caparon M, et al. Urinary tract infections: epidemiology, mechanisms of infection and treatment options. Nat Rev Microbiol 2015;13(5):269-84.

[7] Gupta A, Chauhan B, Pethani J, et al. Fluoroquinolones resistance among uropathogens at a tertiary-care hospital, Ahmedabad. Int J Med Sci Public Health 2016;5(8):1583-7.

[8] Paul R. State of the Globe: rising antimicrobial resistance of pathogens in urinary tract infection. J Glob Infect Dis 2018;10(3):117-8.

[9] Bennett JE, Dolin R, Blaser MJ. Mandell Douglas and Bennets principles and practice of infectious diseases. $9^{\text {th }}$ edn. Canada: Elsevier 2019.

[10] Procop GW, Church D, Hall G, et al. Koneman's color atlas and textbook of diagnostic microbiology. $7^{\text {th }}$ edn. Philadelphia: Lippincott, Williams \& Wilkins 2017.

[11] Weisstein MP, Patel JB, Galas MF, et al. Performance standards for antimicrobial susceptibility testing. 28 $8^{\text {th }}$ edn. (CLSI)-M100: Clinical Laboratory Standards Institute 2018:30-8.

[12] Shevade SU, Agrawal GN. Study of community and nosocomial uropathogens and their drug resistance. Natl J Community Med 2013;4(4):647-52.

[13] Alkhyat SH, Al Maqtari MA. Prevalence of microorganisms isolates from urinary tract infections at some hospitals in Sana'a City, Yemen. Int J Curr Microbiol App Sci 2014;3(6):876-85.

[14] Jain S, Sharma M, Kumar M, et al. Prevalence of uropathogens in urinary tract infection and their antimicrobial resistance pattern in a north Delhi hospital, India: a nine year study. Int J Microbiol Res 2014;6(1):545-52.

[15] George CE, Norman G, Ramana GV, et al. Treatment of uncomplicated symptomatic urinary tract infections: resistance patterns and misuse of antibiotics. J Family Med Prim Care 2015;4(3):416-21.

[16] Jayaprakash C, Bai MS. A study of bacterial pathogens and their antibiotic susceptibility profile from community-acquired and hospital-acquired urinary tract infections. J Evol Med Dent Sci 2016;5(27):1400-5.

[17] Kazi MM, Harshe A, Sale H, et al. Catheter Associated Urinary Tract Infections (CAUTI) and antibiotic sensitivity pattern from confirmed cases of CAUTI in a tertiary care hospital: a prospective study. Clin Microbiol $2015 ; 4: 2$.
[18] Kulkarni SR, Peerapur BV, Sailesh KS. Isolation and antibiotic susceptibility pattern of Escherichia coli from urinary tract infections in a tertiary care hospital of North Eastern Karnataka. J Nat Sci Biol Med 2017;8(2):176-80.

[19] Balasubramanyam V, Sharma NL. Clinical profile and Gram negative bacterial profile of urinary tract infection in children attending a tertiary care hospital of Tamilnadu, India. Int J Contemp Pediatr 2017;4(1):2313.

[20] Narasimhaiah M, Annam V, Shetty K. Changing trends in the spectrum of antimicrobial drug resistance pattern of uropathogens isolated from hospitals and community patients with urinary tract infections in Tumkur and Bangalore. Int J Biol Med Res 2011;2(2):504-7.

[21] Vijayganapathy S, Karthikeyan VS, Mallya A, et al. Antimicrobial resistance patterns in a tertiary care nephro-urology center in South India. J Integr Nephrol Androl 2018;5(3):93.

[22] Ren G, Zhou M, Ding N, et al. Analysis on distribution features and drug resistance of clinically isolated Acinetobacter baumannii. Exp Ther Med 2016;12(3):1715-8.

[23] George M, Joseph L, Leena PN, et al. A prospective study comparing nitrofurantoin vs fluoroquinolones in the therapy of uncomplicated urinary tract infection. The Pharma Innovation Journal 2016;5(6):47-52.

[24] Rattanaumpawan P, Tolomeo P, Bilker WB, et al. Risk factors for fluoroquinolone resistance in Gram-negative bacilli causing healthcare-acquired urinary tract infections. J Hosp Infect 2010;76(4):324-7.

[25] Banerjee T, Anupurba S. Risk factors associated with fluoroquinolone-resistant enterococcal urinary tract infections in a tertiary care university hospital in north India. Indian J Med Res 2016;144(4):604-10.

[26] Nandihal NW. Profile of urinary tract infection and quinolone resistance among Escherichia coli and Klebsiella species isolates. Int J Curr Microbiol App Sci 2015;4(7):749-56.

[27] Mandal J, Acharya NS, Buddhapriya D, et al. Antibiotic resistance pattern among common bacterial uropathogens with a special reference to ciprofloxacin resistant Escherichia coli. Indian J Med Res 2012;136(5):842-9.

[28] Tada DG, Gandhi PJ, Patel KN. A study on antibiotic related resistance in UTI patients: a comparison between community acquired and hospital acquired E. coli. Natl J Community Med 2012;3(2):255-8.

[29] Karlowsky JA, Kelly LJ, Thornsberry C, et al. Trends in antimicrobial resistance among urinary tract infection isolates of escherichia coli from female outpatients in the United States. Antimicrob Agents Chemother 2002;46(8):2540-5.

[30] Klein RD, Hultgren SJ.Urinary tract infections: microbial pathogenesis, host-pathogen interactions and new treatment strategies. Nat Rev Microbiol 2020;18(4):21126.

[31] Akram M, Shahid M, Khan AU. Etiology and antibiotic resistance patterns of community-acquired urinary tract infections in J N M C Hospital Aligarh, India. Ann Clin Microbiol Antimicrob 2007;6:4. 